\title{
Chromosomal rearrangements in cattle and pigs revealed by chromosome microdissection and chromosome painting
}

\author{
Alain Pinton ${ }^{\mathrm{a}}$, Alain Ducos ${ }^{\mathrm{a} *}$, Martine Yerle $^{\mathrm{b}}$ \\ ${ }^{a}$ UMR INRA-ENVT cytogénétique des populations animales, \\ École nationale vétérinaire de Toulouse, \\ 23, chemin des Capelles, 31076 Toulouse Cedex 3, France \\ b Laboratoire de génétique cellulaire, \\ Institut national de la recherche agronomique, \\ Auzeville BP 27, 31326 Castanet-Tolosan Cedex, France
}

(Received 12 December 2002; accepted 7 May 2003)

\begin{abstract}
A pericentric inversion of chromosome 4 in a boar, as well as a case of $(2 q-; 5 p+)$ translocation mosaicism in a bull were analysed by chromosome painting using probes generated by conventional microdissection. For the porcine inversion, probes specific for $\mathrm{p}$ arms and $\mathrm{q}$ arms were produced and hybridised simultaneously on metaphases of a heterozygote carrier. In the case of the bovine translocation, two whole chromosome probes (chromosome 5, and derived chromosome 5) were elaborated and hybridised independently on chromosomal preparations of the bull who was a carrier of the mosaic translocation. The impossibility of differentiating chromosomes 2 and der(2) from other chromosomes of the metaphases did not allow the production of painting probes for these chromosomes. For all experiments, the quality of painting was comparable to that usually observed with probes obtained from flow-sorted chromosomes. The results obtained allowed confirmation of the interpretations proposed with G-banding karyotype analyses. In the bovine case, however, the reciprocity of the translocation could not be proven. The results presented in this paper show the usefulness of the microdissection technique for characterising chromosomal rearrangements in species for which commercial probes are not available. They also confirmed that the main limiting factor of the technique is the quality of the chromosomal preparations, which does not allow the identification of target chromosomes or chromosome fragments in all cases.
\end{abstract}

chromosome / rearrangement / microdissection / cattle / pig / chromosome painting

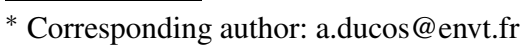




\section{INTRODUCTION}

The chromosomal control programmes carried out in livestock populations, especially in France [7], allow the detection of numerous chromosomal abnormalities [6,8-10,31]. All chromosomal abnormalities have been primarily identified using classical chromosome staining techniques (G-, and/or R-banding). On several occasions, the use of complementary molecular cytogenetic techniques has allowed the improvement of the characterisation of the rearrangements by defining the accurate localisation of the breakpoints, and by demonstrating the reciprocity of some translocations [30,31]. This approach, very classic in humans, is still little used in animal cytogenetics. To our knowledge, only 17 papers have been published so far for farm species: five in the pig [10,23,28,30,31], eight in cattle [12,17-22,29], three in the horse $[1,26,44]$, and one in poultry [32]. One of the reasons is, up to a recent period, the limited availability of probes. Indeed, on the contrary to the human situation, no commercial molecular probe has been developed for livestock species, even for the most important ones (in several studies cited above, e.g. [18,26,28], the fluorescent in situ hybridisation (FISH) experiments were carried out using heterologous human painting probes). Complete or partial collections of chromosome-specific probes have been generated by flow sorting for numerous species including the pig [25,45], cow [35], sheep [2] and chicken [14]. Nevertheless, the complexity of the karyotypes does not always allow the separation of all chromosomes. For instance, no more than twentytwo among thirty chromosome types have been separated as pure fractions for the cow, and for the swine, chromosomes 9 and $\mathrm{X}$ remain unresolved by flow cytometry. Unlike flow-sorting techniques which are limited to the chromosomes that can be isolated as peaks on bivariate sorting profiles, the microdissection strategy can be applied to any chromosome of any species with cytogenetically identifiable chromosomes [15]. In addition, it also allows the production of chromosome-arm or chromosome-band probes. The use of this technique for the characterisation of chromosomal rearrangements has been frequently reported in man (e.g. [42,43]), but rarely in animals [24,34]. Indeed, the few applications in livestock species have been mainly aimed at developing genomic libraries for specific regions of interest (e.g. [33,41]). Painting probes have been produced by microdissection, for instance in cattle, pigs and horses $[3,13,24]$, as well as chickens $[14,16,46]$, but mainly for comparative Zoo-FISH purposes. In this paper, we report the use of conventional microdissection for the production of whole chromosome and chromosome arm painting probes, and their use for the subsequent accurate characterisation of two distinct chromosomal rearrangements: (1) a pericentric inversion of chromosome 4 in a boar, and (2) a mosaic with $15 \%$ of the cells bearing a $2 / 5$ translocation in a bull. 


\section{MATERIALS AND METHODS}

\subsection{Animals - Previous identification of the chromosomal rearrangements}

\subsubsection{Porcine case}

The first abnormality (pericentric inversion of one chromosome 4) was initially identified using GTG-banding in four young Large White boars used in artificial insemination centres. The chromosomal rearrangement has been described, according to the standard nomenclature, as 38, XY, inv(4) (p14;q23) [5]. No phenotypic effect was associated to this particular balanced rearrangement. The fertility of the heterozygous boars (average prolificacy of their mates) was unaltered.

\subsubsection{Bovine case}

The second rearrangement was identified in a young bull of the Blonde d'Aquitaine breed. Two kinds of cells were found in the lymphocyte culture: normal ones $(60, \mathrm{XY})$, and cells carrying a translocation. The chromosomes involved in the rearrangement (BTA2 and BTA5) were identified on GTGbanding preparations. The presence of translocated cells in other tissues (skin fibroblast) allowed us to demonstrate the mosaic nature of the rearrangement. The overall rate of translocated cells was $15 \%$. This chromosomal abnormalilty appeared de novo (the parents had normal karyotypes). No phenotypic abnormality was observed on the carrier. Its fertility could not be estimated since the owner culled it before reproduction.

\subsection{Chromosomal preparations}

The mitotic chromosomes used for microdissection and chromosome painting were obtained from classical Pokeweed stimulated lymphocyte cultures (see [6] for details). Hypotonic treatment (1/6 calf serum) was followed by a soft fixation in methanol:acetic acid 3:1 (3 series of $2 \mathrm{~min}$ ). Chromosome preparations were spread onto grease-free cover slips, treated with $0.1 \%$ Trypsin (Difco, Becton Dickinson, Sparks, USA) and stained with 3\% Giemsa solution to generate GTG banding.

\subsection{Microdissection}

Conventional microdissection was first used to generate SSC4p arm and $\mathrm{SSC} 4 \mathrm{q}$ arm probes (characterisation of the porcine pericentric inversion). For the analysis of the bovine translocation, normal chromosomes 5 and chromosome 5 derivatives were scraped to generate two distinct whole chromosome probes. Microdissection was performed using glass microneedles made using a 
Narishige vertical pipette puller. Chromosome scraping was carried out under an inverted Zeiss microscope using a Narishige micromanipulator, according to the Engelen protocol [11] with slight modifications. Briefly, the porcine chromosome $4 \mathrm{p}$ arms were first dissected on dry slides. The metaphase of interest was then covered with $2 \mu \mathrm{L}$ of sterile distilled water. The 4 to 5 fragments generated stuck instantly to the needle tip and were collected. The remaining $4 \mathrm{q}$ arm fragments became sticky and could then be collected as a whole with a new microneedle. The normal and der(5) bovine chromosomes were microdissected as explained above for the chromosome $4 \mathrm{q}$ arms. Twenty copies of each arm or chromosome were collected and transferred to a $5 \mu \mathrm{L}$ collection drop containing $40 \mathrm{mmol} \cdot \mathrm{L}^{-1}$ Tris- $\mathrm{HCl}, \mathrm{pH} 7.5,20 \mathrm{mmol} \cdot \mathrm{L}^{-1}$ $\mathrm{MgCl}_{2}, 50 \mathrm{mmol} \cdot \mathrm{L}^{-1} \mathrm{NaCl}, 200 \mu \mathrm{mol} \cdot \mathrm{L}^{-1}$ of each dNTP, 1 unit of Topoisomerase (Promega, Madison, USA) and 5 pmol of universal DOP-PCR primer 5'-CCGACTCGAGNNNNNNTGTGG-3' [40].

\subsection{Elaboration of the painting probes, hybridisation and image analysis}

Amplification of microdissected DNA was performed according to [13], i.e. 8 initial cycles at a low annealing temperature $\left(94,30\right.$, and $\left.72^{\circ} \mathrm{C}\right)$ using a sequenase version 2.0 DNA polymerase (Usb, Amersham, Orsay, France), followed by 40 cycles at a higher temperature $\left(94,56\right.$, and $\left.72^{\circ} \mathrm{C}\right)$ using an AmpliTaq DNA polymerase (Applied Biosystems, Foster City, USA). Amplified microdissected products were subsequently labelled with $100 \mu \mathrm{mol} \cdot \mathrm{L}^{-1}$ biotin-16-dUTP or digoxygenin-11-dUTP (Boeringher, Mannheim, Germany) in a 20 cycle PCR identical to that cited above. The PCR products were then purified through G50 chromatography columns and precipitated with $15 \mu \mathrm{g}$ of competitor DNA at $-20^{\circ} \mathrm{C}$ overnight. The pellet was suspended in $10 \mu \mathrm{L}$ of classical hybridisation mixture. Hybridisation, signal detection and image treatment were performed as described in [30].

\section{RESULTS}

The initial DOP-PCR products were first analysed by electrophoresis in a $0.8 \%$ agarose gel (generation of 200 to $800 \mathrm{bp}$ DNA fragments for all microdissected chromosomes or chromosome arms).

\subsection{Porcine case: $\operatorname{inv}(4)(\mathbf{p 1 4} ; \mathbf{q 2 3})$}

The specificity of the $4 p$ and $4 q$ arm probes was first tested using single colour FISH on metaphases of a normal pig. Clear and strong specific signals could be observed. These two probes were then labelled differently and hybridised 
simultaneously on metaphases of an animal heterozygous for the pericentric inversion ( $\mathrm{p}$ arm probe revealed with Texas-Red, $\mathrm{q}$ arm probe revealed with FITC). The normal ( $1 \mathrm{arm}=1$ colour) and inverted ( 1 arm $=2$ colours $)$ chromosomes could be clearly distinguished (Fig. 1). This experiment allowed us to demonstrate without ambiguity the nature of the rearrangement and to determine precisely the size of the chromosome fragments involved.

\subsection{Bovine case: $2 q-/ 5 p+$ translocation}

The chromosome 5 probe generated by microdissection (biotin-labelled and revealed by FITC) was first hybridised on metaphases of the bull who was a carrier of the mosaic translocation. The analysis of normal cells allowed us to confirm the probe specificity (Fig. 2a). The analysis of cells carrying the translocation revealed two signals (Fig. 2b). One corresponded to the normal BTA5 chromosome (chromosome entirely stained), and the other one to the der(5) chromosome, exhibiting an unstained fragment corresponding to the chromosomal material translocated from one chromosome 2.

The der(5) chromosome probe produced was then hybridised on similar chromosome preparations. Four clear signals could be distinguished on normal cells (Fig. 3a). The two entirely stained chromosomes corresponded to the normal BTA5 chromosomes. The remaining two corresponded to the normal partially labelled BTA2 chromosomes. The determination of the size of the stained segments on these chromosomes allowed us to confirm the location of the breakpoint on chromosome $2 q 33$. The analysis of the cells carrying the translocation revealed three painted chromosomes (Fig. 3b): as expected, one normal chromosome 5 and the der(5) chromosome appeared entirely stained, whereas only the $2 \mathrm{q} 33 \rightarrow$ 2qter segment of the normal chromosome 2 was painted. These experiments allowed us to clearly demonstrate the translocation of one $2 \mathrm{q} 33 \rightarrow 2 \mathrm{qter}$ segment to one chromosome 5 . On the contrary, the reciprocal translocation of a centromeric (very short) fragment of one chromosome 5 to the der(2) chromosome could not be proven.

\section{DISCUSSION}

The first application of chromosome microdissection in animal genetics (livestock species) dates back to 1994 [36]. The aim was then to develop a bovine genomic library from scraped Robertsonian 1/29 translocated chromosomes. The majority of the applications that followed had the same mapping purposes. On the contrary, the microdissection-based characterisation of chromosomal rearrangements in farm species has been reported only once before [26]. The results shown in the current paper illustrate the validity of this strategy. In both cases, the probes obtained produced specific and bright paints, comparable to those obtained using homologous probes from 

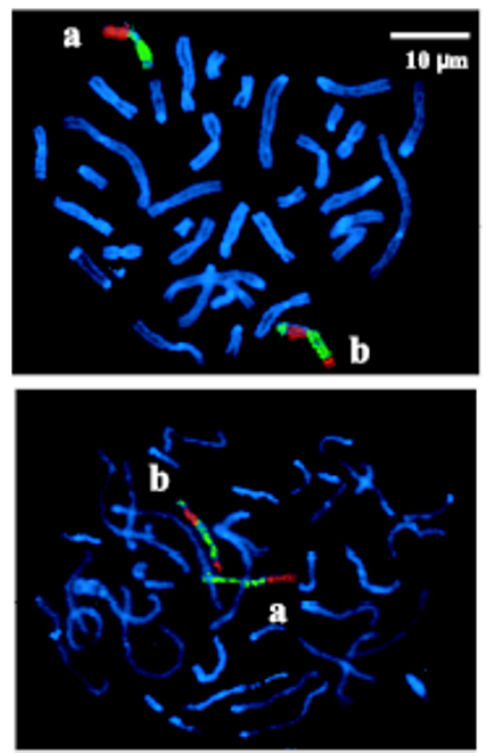

Figure 1.
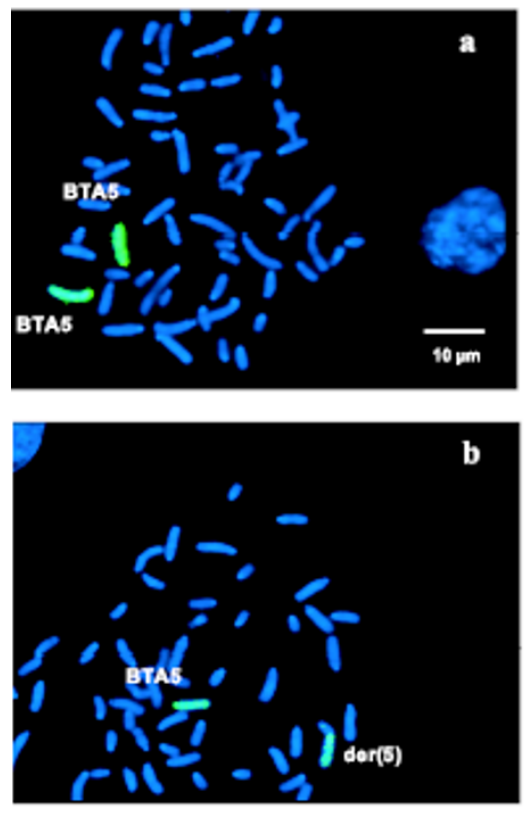

Derivative chromosome 5: der(5)

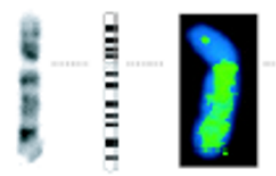

Normal chromosome 5: BTA5

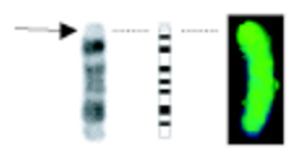

Inverted chromos ome 4 (b)

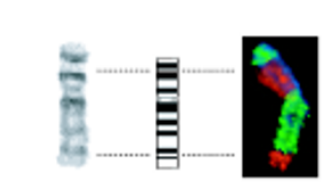

Normal chromosome 4 (a)

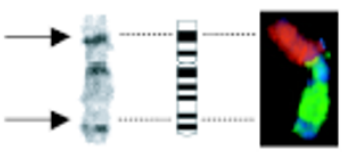

Figure 2. 
Figure 1. Hybridisation of SSC4p (in red) and SSC4q arm (in green) probes on metaphases of a boar heterozygous for the inv(4)(p14;q23) pericentric inversion; (a) normal chromosomes, and (b) inverted chromosomes. On the left: FISH signals observed on complete metaphases. On the right: details (GTG-banding chromosomes, ideograms, and FISH signals). The arrows indicate the putative breakpoints on chromosome 4.

Figure 2. Hybridisation of the BTA5 painting probe on normal (a) and translocated (b) metaphases. On the left: FISH signals observed on complete metaphases. On the right: details (GTG-banding chromosomes, ideograms, and FISH signals). The arrow indicates the putative breakpoint on chromosome 5 .
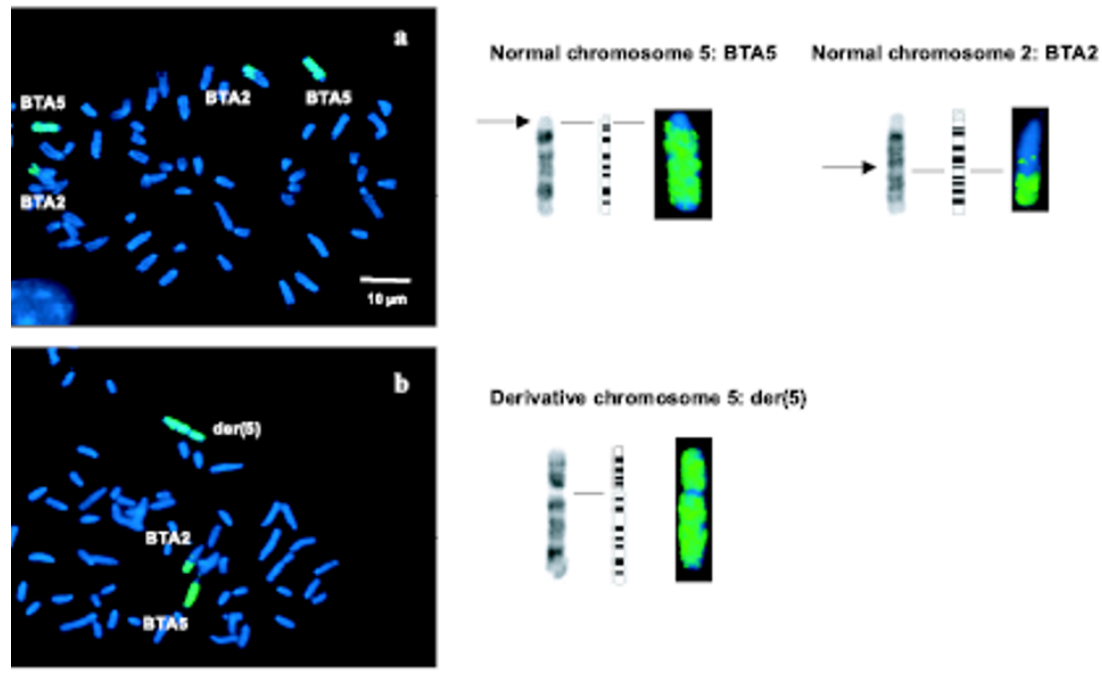

Derivative chromcsome 5: der(5)

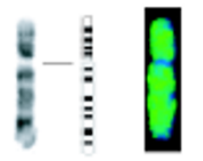

Figure 3. Hybridisation of the der(5) painting probe on normal (a) and translocated (b) metaphases. On the left: FISH signals observed on complete metaphases. On the right: details (GTG-banding chromosomes, ideograms, and FISH signals). The arrows indicate the putative breakpoints on chromosomes 5 and 2.

flow-sorted chromosomes. Therefore, for species presenting complex karyotypes, microdissection can allow the production of painting probes specific for each chromosome while this is not possible by fow cytometry (for instance, specific and separate SSC9 and SSCX probes have been produced in our laboratory using this technique). In addition, it is the only way to produce painting probes specific of a chromosomal arm or of a smaller chromosomal region. The potential applications of such paint probes are numerous (accurate characterisation of chromosomal rearrangements, between species chromosome comparisons, phylogeny, i.e. analysis of karyotype evolution etc.). 
For instance, microdissection could be used to produce the probes that are necessary to develop the pig 20 colour karyotype, as well as multicolour banding probes for particular chromosomes or chromosome sets [27]. This kind of approach (SKY-FISH [37], M-FISH [39]) could allow, as in man, the identification of chromosomal rearrangements that would have escaped detection using standard chromosome banding techniques [38]. Some explanations could be brought forward in cases of severe hypoprolific boars for which no chromosomal rearrangements were detected on GTG-banded karyotypes [9].

The most satisfying results presented in this paper concerned the porcine pericentric inversion. They allowed the validation of the hypothesis put forward after the preliminary analyses [5] (Fig. 1), and helped to accurately locate the breakpoints.

The results obtained for the bovine translocation were also interesting since they confirmed the nature of the chromosomes involved in the rearrangement, and also improved the localisation of the breakpoint on the BTA2 chromosome. A complete analysis however, would have required the hybridisation of the complementary painting probe for chromosome 2 and/or derivative chromosome 2 . Unfortunately, it is very difficult to identify these chromosomes without ambiguity on the metaphases. For instance, BTA2 appeared to be very similar to BTA1 on medium quality preparations, and the derivative chromosome 2 was a small chromosome very similar to BTA12 or BTA15. The quality of our preparations was clearly insufficient to face the isolation of 20 copies of each of these chromosomes. The quality of the spreading was especially poor, due to the particular fixation procedure carried out, which is necessary in order not to compromise the amplification of the microdissected material. A new strategy has been recently proposed [4] that allows the production of efficient paint probes from only one copy of microdissected material, using in situ DOPPCR. This approach could be of help to overcome the problems discussed above, mainly due to the difficult detection of the target chromosomes on poor quality preparations. The simultaneous dual-colour hybridisation, on translocated chromosomes, of a BTA5 painting probe and of two BAC (or cosmid) probes located at the extremities of the fragment translocated from BTA2 could also have definitively proven the origin of the non-stained chromosome fragment on the der(5) chromosome (Fig. 2b). In addition, the breakpoint on BTA5 being located in the centromeric region, another strategy, using for instance a centromeric probe specific for this chromosome (FISH or primed in situ DNA labelling - PRINS), could have been interesting. Unfortunately, such a probe is not yet available in cattle. Nevertheless, the analysis of the banding karyotypes as well as the painting results obtained here allowed a rather clear determination of the chromosomes involved in the rearrangement. This level of analysis is quite sufficient in this particular case since only one animal bearing this abnormality has been detected up to now. 


\section{REFERENCES}

[1] Breen M., Langford C.F., Carter N.P., Fischer P.E., Marti E., Gerstenberg C., Allen W.R., Lear T.L., Binns M.M., Detection of equine X chromosome abnormalities in equids using a horse $\mathrm{X}$ whole chromosome paint probe (WCPP), Vet. J. 153 (1997) 235-238.

[2] Burkin D.J., O’Brien P.C., Broad T.E., Hill D.F., Jones C.A., Wienberg J., Ferguson Smith M.A., Isolation of chromosome specific paints from high resolution flow karyotypes of the sheep (Ovis aries), Chromosome Res. 5 (1997) 102-108.

[3] Chaudhary R., Kijas J., Raudsepp T., Guan X.Y., Zhang H., Chowdhary B.P., Microdissection of pig chromosomes: dissection of whole chromosomes, arms and bands for construction of paints and libraries, Hereditas 128 (1998) 265-271.

[4] Christian A.T., Garcia H.E., Tucker J.D., PCR in situ followed by microdissection allows whole chromosome painting probes to be made from single microdissected chromosomes, Mamm. Genome 10 (1999) 628-631.

[5] Ducos A., Pinton A., Seguela A., Berland H.M., Blanc M.F., Sans P., Darré A., Pinton P., Yerle M., Darré R., Pericentric inversion of the chromosome No. 4 in pig, Genet. Sel. Evol. 29 (1997) 383-394.

[6] Ducos A., Berland H.M., Pinton A., Guillemot E., Seguela A., Darre A., Darre R., Nine new cases of reciprocal translocation in the domestic pig, J. Hered. 89 (1998) 136-142.

[7] Ducos A., Berland H.M., Pinton A., Séguéla A., Brun-Baronnat C., Darré A., Darré R., Contrôle chromosomique des populations animales d'élevage, INRA Prod. Anim. 13 (2000) 25-35.

[8] Ducos A., Dumont P., Séguéla A., Pinton A., Berland H.M., Brun-Baronnat C., Darré A., Marquant-Le Guienne B., Humblot P., Boichard D., Darré R., A new reciprocal translocation in a subfertile bull, Genet. Sel. Evol. 32 (2000) 589-598.

[9] Ducos A., Pinton A., Séguéla A., Berland H.M., Brun-Baronnat C., Bonnet N., Darré R., Contrôle chromosomique des populations porcines en France : bilan de 5 années d'activité, Journ. Rech. Porcine 34 (2002) 269-275.

[10] Ducos A., Pinton A., Yerle M., Séguéla A., Berland H.M., Brun-Baronnat C., Darré R., Cytogenetic and molecular characterization of 8 new reciprocal translocations in the pig species. Estimation of their incidence in the French populations, Genet. Sel. Evol. 34 (2002) 389-406.

[11] Engelen J.J., Albrechts J.C., Hamers G.J., Geraedts J.P., A simple and efficient method for microdissection and microFISH, J. Med. Genet. 35 (1998) 265-268.

[12] Gallagher D.S., Lewis B.C., De Donato M., Davis S.K., Taylor J.F., Edwards J.F., Autosomal trisomy $20(61, \mathrm{XX},+20)$ in a malformed bovine fetus, Vet. Pathol. 36 (1999) 448-451.

[13] Goldammer T., Weikard R., Brunner R.M., Schwerin M., Generation of chromosome fragment specific bovine DNA sequences by microdissection and DOPPCR, Mamm. Genome 7 (1996) 291-296.

[14] Griffin D.K., Haberman F., Masabanda J., O Brien P., Bagga M., Sazanov A., Smith J., Burt D.W., Ferguson Smith M., Wienberg J., Micro- and machrochromosome paints generated by flow cytometry and microdissection: tools for mapping the chicken genome, Cytogenet. Cell Genet. 87 (1999) 278-281. 
[15] Guan X.Y., Meltzer P.S., Trent J.M., Rapid generation of whole chromosome painting probes (WCPs) by chromosome microdissection, Genomics 22 (1994) 101-107.

[16] Guiller-Gencik Z., Bernheim A., Coullin P., Generation of whole chromosome painting probes specific to each chicken macrochromosome, Cytogenet. Cell Genet. 87 (1999) 282-285.

[17] Iannuzzi L., Di Meo G.P., Perucatti A., Eggen A., Incarnato D., Sarubbi F., Cribiu E.P., A pericentric inversion in the cattle Y chromosome, Cytogenet. Cell Genet. 94 (2001) 202-205.

[18] Iannuzzi L., Molteni L., Di Meo G.P., Perucatti A., Lorenzi L., Incarnato D., De Giovanni A., Succi G., Gustavsson I., A new balanced autosomal reciprocal translocation in cattle revealed by banding techniques and human painting probes. Cytogenet. Cell Genet. 94 (2001) 225-228.

[19] Iannuzzi L., Molteni L., Di Meo G.P., De Giovanni A., Perucatti A., Succi G., Incarnato D., Eggen A., Cribiu E.P., A case of azoospermia in a bull carrying a Y-autosome reciprocal translocation, Cytogenet. Cell Genet. 95 (2001) 225-227.

[20] Iannuzzi L., Di Meo G.P., Leifsson P.S., Eggen A., Christensen K., A case of trisomy 28 in cattle revealed by both banding and FISH-mapping techniques, Hereditas 134 (2001) 147-151.

[21] Joerg H., Garner D., Rieder S., Suwattana D., Stranzinger G., Molecular genetic characterization of Robertsonian translocations in cattle, J. Anim. Breed. Genet. 118 (2001) 371-377.

[22] Kawakura K., Miyake Y., Murakami R.K., Kondoh S., Hirata T.I., Kaneda Y., Abnormal structure of the Y chromosome detected in bovine gonadal hypoplasia (XY female) by FISH, Cytogenet. Cell Genet. 76 (1997) 36-38.

[23] Konfortova G.D., Miller N.G.A., Tucker E.M., A new reciprocal translocation $(7 q+; 15 q-)$ in the domestic pig, Cytogenet. Cell Genet. 71 (1995) 285-288.

[24] Kubickova S., Cernohorska H., Mulisova P., Rubes J., The use of laser microdissection for the preparation of chromosome-specific painting probes in farm animals, Chromosome Res. 10 (2002) 571-577.

[25] Langford C.F., Telenius H., Miller N.G., Thomsen P.D., Tucker E.M., Preparation of chromosome-specific paints and complete assignment of chromosomes in the pig flow karyotype, Anim. Genet. 24 (1993) 261-267.

[26] Lear T.L., Layton G., Use of Zoo-FISH to characterise a reciprocal translocation in a thoroughbred mare $\mathrm{t}(1 ; 16)$ (q16;q21.3), Equine Vet. J. 34 (2002) 207-209.

[27] Liehr T., Heller A., Starke H., Rubtsov N., Trifonov V., Mrasek K., Weise A., Kuechler A., Claussen U., Microdissection based high resolution multicolor banding for all 24 human chromosomes, Int. J. Mol. Med. 9 (2002) 335-339.

[28] Mäkinen A., Andersson M., Nikunen S., Detection of the X chromosomes in a Klinefelter boar using a whole human X chromosome painting probe, Anim. Reprod. Sci. 52 (1998) 317-323.

[29] Miyake Y.I., Kawakura K., Murakami R.K., Kaneda Y., Minute fragment observed in a bovine pedigree with Robertsonian translocation, J. Hered. 85 (1994) 488-490.

[30] Pinton A., Ducos A., Séguéla A., Berland H.M., Darré R., Darré A., Pinton P., Schmitz A., Cribiu E.P., Yerle M., Characterization of reciprocal translocations 
in pigs using dual-colorchromosome painting and PRINS, Chromosome Res. 6 (1998) 361-365.

[31] Pinton A., Ducos A., Berland H.M., Séguéla A., Brun-Baronnat C., Darré A., Darré R., Yerle M., Chromosomal abnormalities in hypoprolific boars, Hereditas 132 (2000) 55-62.

[32] Ramos P.S., Bitgood J.J., Ponce De Leon A., Novel chromosomal translocation in chicken uncovered by double colour FISH, Anim. Biotechnol. 10 (1999) 119-122.

[33] Sarker N., Hawken R.J., Takahashi S., Alexander L.J., Awata T., Schook L.B., Vasue H., Directed isolation and mapping of microsatellites from swine Chromosome 1q telomeric region through microdissection and RH mapping, Mamm. Genome 12 (2001) 524-527.

[34] Schelling C., Pienkowska A., Arnold S., Hauser B., Switonski M., A male to female sex-reversed dog with a reciprocal translocation, J. Reprod. Fertil. 57 (2001) 435-438.

[35] Schmitz A., Oustry A., Chaput B., Bahri Darwich I., Yerle M., Milan D., Frelat G., Cribiu E.P., The bovine bivariate flow karyotype and peak identification by chromosome painting with PCR-generated probes, Mamm. Genome 6 (1995) $415-420$.

[36] Schmutz S.M., Berryere T.G., Moker J.S., Thue T.D., Winkelman D.C., Gene mapping from a bovine 1,29 DNA library prepared with chromosome microdissection, Mamm. Genome 5 (1994) 138-141.

[37] Schröck E., Du Manoir S., Veldman T., Schoell B., Wienberg J., Ferguson Smith M.A., Ning Y., Ledbetter D.H., Bar Am I., Soenksen D., Garini Y., Ried T., Multicolor spectral karyotyping of human chromosomes, Science 273 (1996) 494-497.

[38] Schröck E., Veldman T., Padilla-Nash H., Ning Y., Spurbeck J., Jalal S., Shaffer L.G., Papenhausen P., Kozma C., Phelan M.C., Kjeldsen E., Schonberg S.A., O Brien P., Biesecker L., du Manoir S., Ried T., Spectral karyotyping refines cytogenetic diagnostics of constitutional abnormalities, Hum. Genet. 101 (1997) 255-262.

[39] Speicher M.R., Ballard S.G., Ward D.C., Karyotyping human chromosomes by combinatorial multi-fluor FISH, Nature Genet. 12 (1996) 368-375.

[40] Telenius H., Carter N., Bebb C.E., Nordenskjold M., Ponder Bruce A.J., Tunnacliffe A., Degenerated oligonucleotide-primed PCR: general amplification of target DNA by a single degenerated primer, Genomics 13 (1992) 718-725.

[41] Weikard R., Kühn C., Goldammer T., Laurent P., Womack J.E., Schwerin M., Targeted construction of a high-resolution, integrated, comprehensive, and comparative map for a region specific to bovine chromosome 6 based on radiation hybrid mapping, Genomics 79 (2002) 768-76.

[42] Weimer J., Kiechle M., Senger G., Wiedemann U., Ovens Raeder A., Schuierer S., Kautza M., Siebert R., Arnold N., An easy and reliable procedure of microdissection technique for the analysis of chromosomal breakpoints and marker chromosomes, Chromosome Res. 7 (1999) 366-362.

[43] Weimer J., Kiechle M., Arnold N., FISH-microdissection (FISH-MD) analysis of complex chromosome rearrangements, Cytogenet. Cell Genet. 88 (2000) 114118. 
[44] Wieczorek M., Switonski M., Yang F., A low-level X chromosome mosaicism in mares, detected by chromosome painting, J. Appl. Genet. 42 (2001) 205-209.

[45] Yerle M., Schmitz A., Milan D., Chaput B., Monteagudo L., Vaiman M., Frelat G., Gellin J., Accurate characterization of porcine bivariate flow karyotype by PCR and fluorescence in situ hybridisation, Genomics 16 (1993) 97-103.

[46] Zimmer R., King W.A., Verrinder Gibbins A.M., Generation of chicken Zchromosome painting probes by microdissection for screening large insert genomic libraries, Cytogenet. Cell Genet. 78 (1997) 124-130.

To access this journal online: www.edpsciences.org 